\title{
Soft magnetic properties of Electrodeposited Fe-Ni Films Prepared in Citric Acid Based Bath
}

\author{
T. Shimokawa ${ }^{1}$, T. Yanai ${ }^{1}$, K. Takahashi ${ }^{1}$, M. Nakano ${ }^{1}$, K. Suzuki ${ }^{2}$, and H. Fukunaga ${ }^{1}$, Member, IEEE \\ ${ }^{1}$ Graduate School of Engineering, Nagasaki University, Nagasaki 852-8521, Japan \\ ${ }^{2}$ Department of Material Engineering, Monash University, Melbourne 3800, Australia
}

\begin{abstract}
Electrodeposited Fe-Ni films are widely used in device applications. However, there is a growing awareness of the toxicity of the plating bath containing boric acid. In order to avoid boric acid in the deposition process, we have employed a citric acid based bath for electrodeposition of Fe-Ni films and investigated the effect of the acid content in the bath on the structural and magnetic properties of the deposited films. It is found that the Fe content of the film depends largely on the acid concentration and low coercivity values of less than $30 \mathrm{~A} / \mathrm{m}$ are realized when the Fe content of the film is around 22 at.\%. This magnetic softness is attainable in a wide film thickness range between 20 and $120 \mu \mathrm{m}$. Our process exhibits a relatively high cathode efficiency of above $55 \%$. Furthermore, a high deposition rate of $170 \mu \mathrm{m} / \mathrm{h}$ is obtained without sacrificing the magnetic softness of the film by increasing the current density during the deposition. From these results, we conclude that the citric acid based bath is an environmentally friendlier plating bath ideal for mass-production of magnetically soft Fe-Ni films.
\end{abstract}

Index Terms - Soft magnetic material, Electrodepositon, Permalloy, Film

\section{INTRODUCTION}

$F^{e}$ e-Ni alloys exhibit good soft magnetic properties such as low coercivity and high permeability and have been applied in a range of electric devices for the purpose of shielding and converging magnetic flux. Both the magnetocrystalline anisotropy and magnetostriction constants become nearly zero at an alloy composition of $\mathrm{Fe}_{22} \mathrm{Ni}_{78}$ and thus, this alloy is well-known for its excellent soft magnetic properties [1]. The $\mathrm{Fe}-\mathrm{Ni}$ films in the electric device applications are commonly prepared by electrodeposition because of the high economic viability of the process as well as the simplicity of fabrication equipment.

Currently, the commonly used plating bath for the Fe-Ni films contains boric acid for the purpose of controlling $\mathrm{pH}$ of the bath. Although the boric acid plays an important role in the plating process of $\mathrm{Ni}$ and $\mathrm{Fe}$ films [2,3], the waste bath containing boron is harmful and thus, restricted by the regulation of environmental protection in Japan [4]. Doi et. al. reported that a plating bath containing citric acid is effective in obtaining fine crystalline $\mathrm{Ni}$ films free of texture effects by plating [5,6]. It is well known that fine crystal structures are effective in realizing good soft magnetic properties due to the exchange softening effect [7-10]. Therefore, Fe-Ni films prepared by electroplating using citric acid instead of the harmful boric acid could be a potential candidate for the substitution of the boric acid based bath in the plating process of soft magnetic Fe-Ni films. In this report, in order to clarify the potential of the citric acid based bath, we have investigated the structural and magnetic properties of electrodeposited FeNi films prepared from a plating bath containing citric acid.

Manuscript received March 2, 2012. Corresponding author: T. Yanai (email: t-yanai@nagasaki-u.ac.jp).

Digital Object Identifier inserted by IEEE

\section{EXPERIMENTAL PROCEDURES}

\section{A. Preparation of electrodeposited Fe-Ni films}

The base electrolyte of the plating bath contained the following: $275 \mathrm{~g} / \mathrm{L}$ of $\mathrm{NiSO}_{4} \cdot 6 \mathrm{H}_{2} \mathrm{O}, 35 \mathrm{~g} / \mathrm{L}$ of $\mathrm{FeSO}_{4} \cdot 7 \mathrm{H}_{2} \mathrm{O}, 50$ $\mathrm{g} / \mathrm{L}$ of $\mathrm{NaCl}$ and $5 \mathrm{~g} / \mathrm{L}$ of $\mathrm{C}_{7} \mathrm{H}_{4} \mathrm{NNaO}_{3} \mathrm{~S} \cdot 2 \mathrm{H}_{2} \mathrm{O}$. We added 0 $300 \mathrm{~g} / \mathrm{L}$ of citric acid $\left(\mathrm{C}_{6} \mathrm{H}_{8} \mathrm{O}_{7} \cdot \mathrm{H}_{2} \mathrm{O}\right)$ to the above-mentioned plating bath. $\mathrm{pH}$ in the bath was not adjusted (approximately 2.2). Anode and cathode used were $500 \mu \mathrm{m}$ thick $\mathrm{Ni}$ and $\mathrm{Cu}$ plates, respectively. The Fe-Ni films were electrodeposited on the $\mathrm{Cu}$ plate. The deposition was typically performed on a plating area of $75 \mathrm{~mm}^{2}$ under a dc current density of 2.0 $\mathrm{mA} / \mathrm{mm}^{2}$ for a deposition time of $10 \mathrm{~min}$. The bath temperature was $50^{\circ} \mathrm{C}$.

\section{B. Measurements}

The thickness and dc-hysteresis loops of the electrodeposited $\mathrm{Fe}-\mathrm{Ni}$ films were measured with a micrometer (Mitutoyo CPM15-25MJ) and a B-H tracer (Riken Denshi BHS-40) operated at a field sweep rate of $50 \mathrm{mHz}$, respectively. The maximum excitation field of approximately $4000 \mathrm{~A} / \mathrm{m}$ was used for the B-H measurements and the coercivity was determined from the loop. The compositions and crystal structures of the films were analyzed by EDX (Hitachi High-technologies S-3000) and XRD (Rigaku Rint 2000), respectively. The thickness and the composition of each $75 \mathrm{~mm}^{2}$-film were determined by averaging the values obtained for approximately every $7 \mathrm{~mm}^{2}$ (12 points) and 9 $\mathrm{mm}^{2}$ (9 points), respectively. All measurements were carried out for the Fe-Ni films in an as-deposited state.

\section{RESULTS AND DISCUSSION}

Figure 1 shows the changes in the coercivity and Fe content 
in the electrodeposited Fe-Ni films as a function of the content of citric acid in plating bath. As shown in Fig.1, the Fe content increases from 18 to 50 at.\% with increasing the content of citric acid from 0 to $100 \mathrm{~g} / \mathrm{L}$. The coercivity shows a dramatic decrease from 380 to $20 \mathrm{~A} / \mathrm{m}$ with increasing the citric acid content from 0 to $30 \mathrm{~g} / \mathrm{L}$ followed by a moderate increase in the higher acid concentrations. Both the Fe content and the coercivity are approximately 50 at.\% and $70 \mathrm{~A} / \mathrm{m}$ and are almost constant for the acid concentrations higher than 100 $\mathrm{g} / \mathrm{L}$.

In order to clarify the effect of Fe content on the coercivity, the coercivity results in Fig. 1 are replotted in Fig. 2 as a function of Fe content. It is clear that the lowest coercivity value is obtained around 22 at.\% of $\mathrm{Fe}$, the well-known composition where both the magnetocrystalline anisotropy and the magnetostriction constants become nearly zero. Thus, the dramatic improvement of the magnetic softness observed in the acid concentration range between 0 and $30 \mathrm{~g} / \mathrm{L}$ is readily understood by the induced change in Fe content. The low coercivity less than $30 \mathrm{~A} / \mathrm{m}$ is due to the realization of the required composition in the film, i.e. $\mathrm{Fe}_{22} \mathrm{Ni}_{78}$.

The coercivity of the films in Fig. 2 remains relatively low even with a high Fe of around 50 at.\% despite the fact that the intrinsic magnetocrystalline anisotropy of the films is expected to be high. In order to understand this behavior, we investigated the structure of the films. Figure 3 shows XRD patterns of the films prepared at various concentrations of citric acid. It is evident on these diffraction patterns that line broadening and a shift of the diffraction angle to the lower angle side take place when the acid concentration is high. The shift of the diffraction angle reflects the effect of Fe content on the lattice parameter of Fe-Ni alloys while the line broadening indicates that higher acid concentrations are effective in reducing the grain size. Since the effective magnetocrystalline anisotropy could be reduced by grain refinement, the relatively low coercivity values at a high $\mathrm{Fe}$ of around 50 at.\% is attributable to the grain refinement effect.

From these results, we found that the Fe-Ni films with relatively low coercivity could be obtained in a wide $\mathrm{Fe}$ content range between 20 and 50 at.\%.

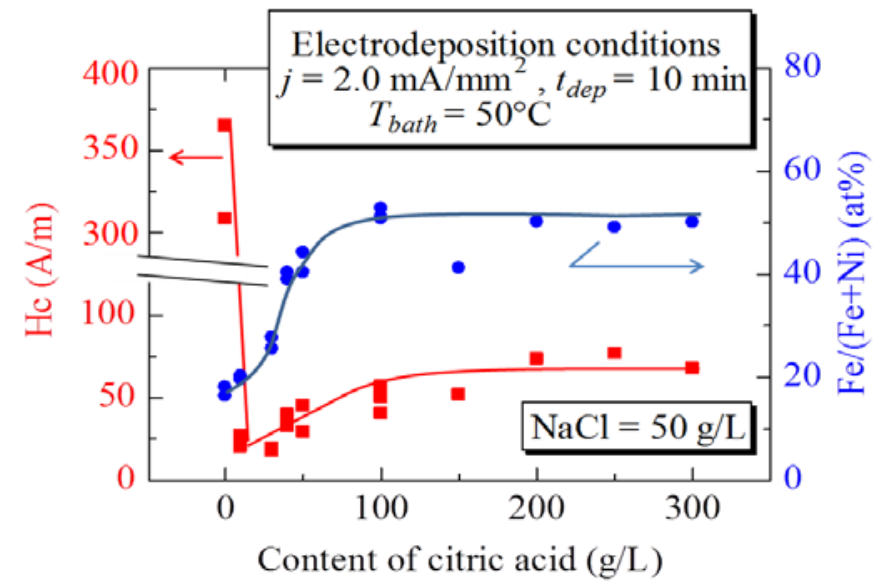

Fig.1 Changes in the coercivity and Fe content in deposited Fe-Ni films as a function of citric acid content in plating bath.

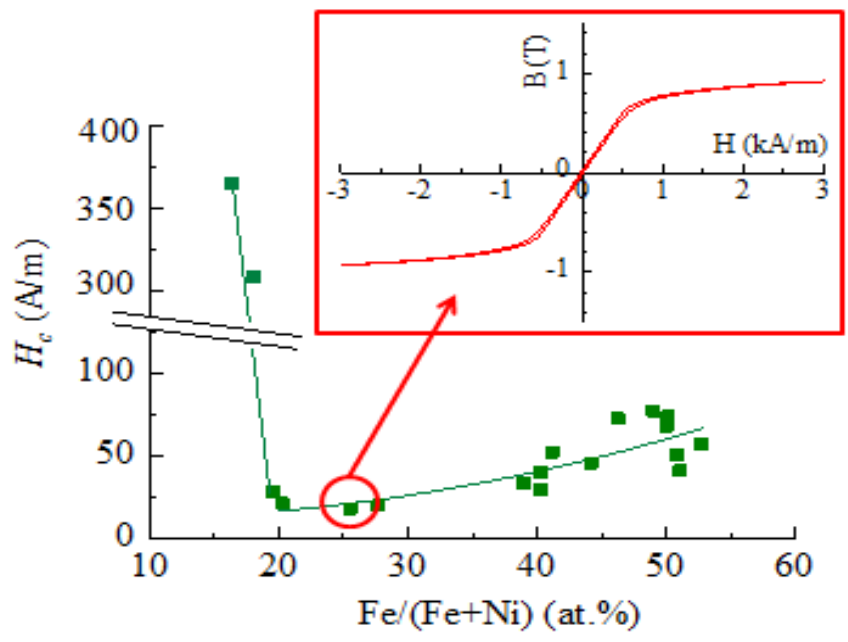

Fig.2 Relationship between the coercivity and Fe content (replot of the results in Fig. 1). The inset shows a typical B-H loop of the film with low coercivity.

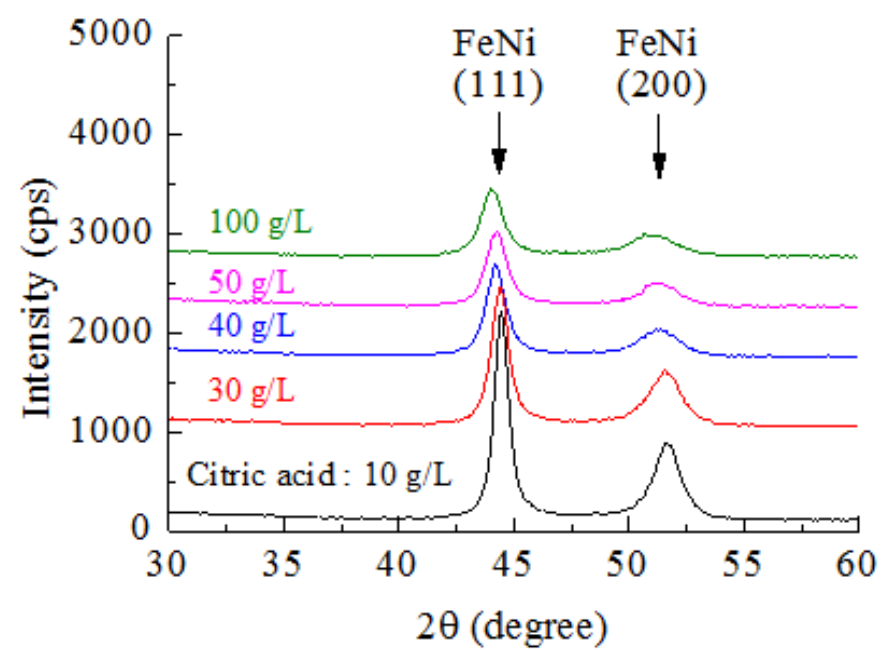

Fig.3 XRD patterns of the films prepared with various contents of citric acid. All the films shown were deposited under the same conditions (a dc current density of $2.0 \mathrm{~mA} / \mathrm{mm}^{2}$, a deposition time of $10 \mathrm{~min}$, a bath temperature of 50 ${ }^{\circ} \mathrm{C}$ and a plating area of $75 \mathrm{~mm}^{2}$ ).

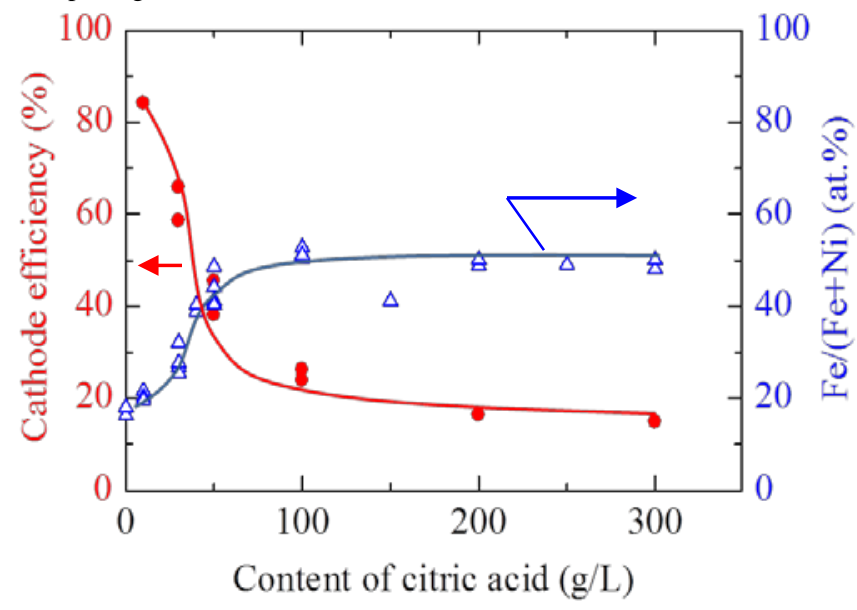

Fig.4 Changes in cathode efficiency and Fe content as a function of the citric acid content in the plating bath. The cathode efficiency was obtained from the actual and theoretical weights of the electrodeposited Fe-Ni films. The theoretical weight was calculated by Faraday's low based on the alloy composition of the film. 
High deposition rate has an advantage in mass production because required film thickness could be obtained in a short deposition time. Since the deposition rate for the plating process in an aqua bath is often limited by generation of hydrogen, the cathode efficiency is one of the most important parameters for realization of high-rate electric plating. Hence, we investigated the cathode efficiency by comparing the experimental and theoretical film mass; the cathode efficiency is defined by the actual weight of electrodeposited Fe-Ni film divided by the theoretical weight as per Faraday's law. Figure 4 shows the cathode efficiency as a function of citric acid content in the plating bath. The film compositions are also shown in Fig. 4. It is clear that the cathode efficiency shows a tendency to decrease with increasing the content of citric acid whereas the Fe content exhibits an opposite trend. It is worth mentioning here that the cathode efficiency remains a high value above $55 \%$ with $20-30 \mathrm{~g} / \mathrm{L}$ of citric acid where the ideal film composition of $\mathrm{Fe}_{22} \mathrm{Ni}_{78}$ is realized. According to previous reports on the Fe-Ni films prepared in a boric acid based bath, the cathode efficiency at Fe content of around 22 at.\% was approximately $60 \%$ [11-13]. Consequently, it is confirmed that the cathode efficiency for our citric acid based bath is comparable to that in the boric acid based bath.

Figure 5 shows the changes in the film thickness and the coercivity for the electrodeposited Fe-Ni films as a function of deposition time. In addition to a current density $(j)$ of 2.0 $\mathrm{mA} / \mathrm{mm}^{2}, j=1.3$ and $2.7 \mathrm{~mA} / \mathrm{mm}^{2}$ were also used in the deposition process. As shown in Fig. 5, the film thickness increases proportionately with deposition time for all the three current densities. However, the coercivity at each current density appears almost unaffected by the deposition time up to $40 \mathrm{~min}$, although the coercivity values of the films deposited at $j=1.3 \mathrm{~mA} / \mathrm{mm}^{2}$ are clearly higher than those for the higher current densities. We have confirmed that the Fe content in the film at $j=1.3 \mathrm{~mA} / \mathrm{mm}^{2}$ is slightly higher than the ideal alloy composition and the poorer magnetic softness for $j=1.3$ $\mathrm{mA} / \mathrm{mm}^{2}$ can be explained by this compositional effect. The deposition rates, which were calculated by the slope of the linier fitting lines, were $85 \mu \mathrm{m} / \mathrm{h}$ for $1.3 \mathrm{~mA} / \mathrm{mm}^{2}, 137 \mu \mathrm{m} / \mathrm{h}$ for $2.0 \mathrm{~mA} / \mathrm{mm}^{2}$ and $176 \mu \mathrm{m} / \mathrm{h}$ for $2.7 \mathrm{~mA} / \mathrm{mm}^{2}$. This indicates that the deposition rate is enhanced in proportion to the current density.

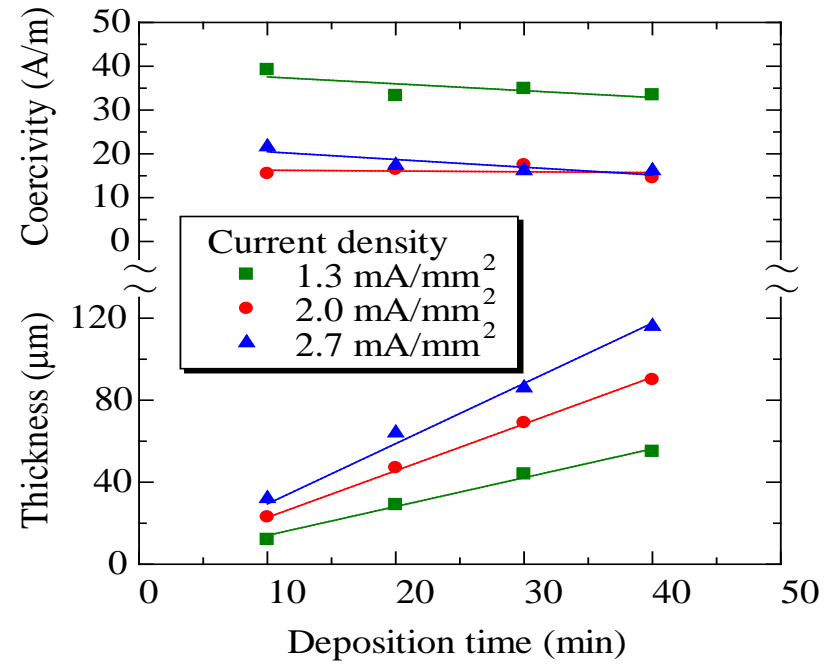

Fig.5 Changes in film thickness and Fe content for the electrodeposited Fe-Ni films as a function of deposition time.

\section{CONCLUSION}

In this report, we have investigated the structural and magnetic properties of electrodeposited Fe-Ni films prepared from a citric acid based bath. The obtained results are summarized as follows:

(1) Fe-Ni films with a low coercivity of less than $30 \mathrm{~A} / \mathrm{m}$ could be obtained around 22 at.\% of Fe.

(2) Fe content was increased with increasing the content of citric acid from approximately 18 at.\% to 50 at.\%

(3) Cathode efficiency was reduced from $80 \%$ to $18 \%$ with increasing the content of citric acid

(4) A high deposition rate of $170 \mu \mathrm{m} / \mathrm{h}$ could be obtained without deterioration of good soft magnetic property of the film

(5) Fe-Ni films with a low coercivity value of $20 \mathrm{~A} / \mathrm{m}$ were obtained in a wide thickness range of 20 to $120 \mu \mathrm{m}$.

From above-mentioned results, we conclude that the citric acid based bath is an ideal plating bath for obtaining Fe-Ni films with good soft magnetic properties.

\section{REFERENCES}

[1] R. M. Bozorth, and J. G. Walker, "Magnetic Crystal Anisotropy and Magnetostriction of Iron-Nickel Alloys,"Physical Review, vol. 89, 1953, pp.624-628.

[2] B. V. Tilak, A. S. Gendron, and M. A. Mosoiu, "Borate buffer equilibria in nickel refining electrolytes," Journal of Applied Electrochemistry, vol. 7, 1977, pp. 495-500.

[3] L. A. Toledo-Matos, and M. A. Pech-Canul, "Evolution of an iron passive film in a borate buffer solution," Journal of Solid State Electrochemistry, vol. 15, 2011, pp.1927-1934.

[4] Notification of the Direction General of the Encironment Agency in Japan; 1999.2.22

[5] T. Doi, and K. Mizumoto, "Bright Nickel Plating from Nickel Citrate Electroplating Bath,” Metal Finishing, vol. 102, 2004, pp.26-35. 
[6] T. Doi, and K. Mizumoto, "Effect of Bath $\mathrm{pH}$ on Nickel Citrate Electroplating Bath,” Metal Finishing, vol. 102, 2004, pp.104-111

[7] Y. Yoshizawa, S. Oguma, and K. Yamauchi, "New Fe-based soft magnetic alloys composed of ultrafine grain structure," Journal of Applied Physics, vol. 64, 1988, pp.6044-6046.

[8] K. Suzuki, A. Makino, N. Kataoka, A. Inoue, and T. Masumoto, "High Saturation Magnetization and Soft Magnetic Properties of bcc Fe-Zr-B and Fe-Zr-B-M (M=Transition Metal) Alloys with Nanoscale Grain Size," Materials Transactions JIM, vol. 32, 1991, pp.93-102.

[9] M. A. Willard, M.Q. Huang, D. E. Laughlin, M. E. McHenry, J. O. Cross, V. G. Harris, and C. Franchetti, "Magnetic properties of HITPERM (Fe, Co $)_{88} \mathrm{Zr}_{7} \mathrm{~B}_{4} \mathrm{Cu}_{1}$ magnets," J. Appl. Phys., vol. 85, 1999, pp.4421-4423.

[10] G. Herzer, "Grain size dependence of coercivity and permeability in nanocrystalline ferromagnets," IEEE Transactions on Magnetics, vol. 26, 1990, pp.1397-1402.

[11] Jean-Marie Quemper, S. Nicolas, J. P. Gilles, J. P. Gilles, J. P. Grandchamp, A. Bosseboeuf, T. Bourouina, and E. Dufour-Gergam, "Permalloy electroplating through photoresist molds," Sensors and Actuators, vol. 74, 1999, pp.1-4.

[12] E. R. Spada, L. S. de Oliveira, A. S. da Rocha, A. A. Pasa, G. Zangari, and M. L. Sartorelli, "Thin films of $\mathrm{Fe}_{x} \mathrm{Ni}_{1-x}$ electroplated on silicon (100)," Journal of Magnetism and Magnetic Materials, vol. 272-276, 2004, pp. e891- e892.

[13] B. Koo, and B. Yoo, "Electrodeposition of low-stress NiFe thin films from a highly acidic electrolyte," Surf. Coat. Technol., vol. 205, 2010, pp.740-744, 2010. 